Delft University of Technology

\title{
Evaluation of InSAR data for measuring the surface settlement during shield tunnel construction of the North-South Line in Amsterdam
}

Reinders, K. J.; van Leijen, F. J.; Hanssen, R. F.; Korff, M.

DOI

10.1201/9780429321559-18

Publication date

2021

Document Version

Accepted author manuscript

Published in

Geotechnical Aspects of Underground Construction in Soft Ground - Proceedings of the 10th International Symposium on Geotechnical Aspects of Underground Construction in Soft Ground, IS-CAMBRIDGE 2022

\section{Citation (APA)}

Reinders, K. J., van Leijen, F. J., Hanssen, R. F., \& Korff, M. (2021). Evaluation of InSAR data for measuring the surface settlement during shield tunnel construction of the North-South Line in Amsterdam.

In M. Z. E. B. Elshafie, G. M. B. Viggiani, \& R. J. Mair (Eds.), Geotechnical Aspects of Underground Construction in Soft Ground - Proceedings of the 10th International Symposium on Geotechnical Aspects of Underground Construction in Soft Ground, IS-CAMBRIDGE 2022 (pp. 137-144). (Geotechnical Aspects of Underground Construction in Soft Ground - Proceedings of the 10th International Symposium on Geotechnical Aspects of Underground Construction in Soft Ground, IS-CAMBRIDGE 2022). CRC Press / Balkema - Taylor \& Francis Group. https://doi.org/10.1201/9780429321559-18

Important note

To cite this publication, please use the final published version (if applicable).

Please check the document version above.

\section{Copyright}

Other than for strictly personal use, it is not permitted to download, forward or distribute the text or part of it, without the consent of the author(s) and/or copyright holder(s), unless the work is under an open content license such as Creative Commons.

\section{Takedown policy}

Please contact us and provide details if you believe this document breaches copyrights.

We will remove access to the work immediately and investigate your claim. 


\title{
Evaluation of InSAR data for measuring the surface settlement during shield tunnel construction of the North-South Line in Amsterdam
}

\author{
K.J. Reinders, F.J. van Leijen, R.F. Hanssen \& M. Korff \\ Delft University of Technology, Delft, The Netherlands \\ Faculty of Civil Engineering and Geoscience, Department Hydraulic Engineering
}

\begin{abstract}
This paper investigates the use of InSAR data during shield tunnel construction when short-term settlements occur within a few days. Additionally, the long-term settlement, which occur over several years, in the vicinity of these tunnels are evaluated with inSAR. The North-South Line in Amsterdam is used as a case study for this research. We used the settlement during construction as a-priori information to determine the most likely unwrapping solution for a few selected InSAR points. Then we verified this outcome with the traditional monitoring of the surface levelling points during construction and finally used only the InSAR to evaluate the long-term settlements. We conclude that with prior information InSAR data can be processed correctly and that InSAR can capture the short-term settlement that occur immediately during construction of a shield tunnel. Also, InSAR is a valuable complementary source of information because it provides data outside the area of the levelling points and gives information about settlement patterns prior to and after construction
\end{abstract}

\section{INTRODUCTION}

One of the major risks during and after the construction of underground structures is the development of surface settlements. The occurrence and magnitude of these settlements needs to be known to determine the potential damage to buildings and to select mitigation measures. Prior to the construction of a bored tunnel, the expected short-term settlements and their effects on buildings are computed with empirical methods (Peck 1969, Sagaseta 1987, Mair 1993, Verruijt \& Booker 1996, Loganathan et al. 2001, Selemetas et al. 2006, Kaalberg et al. 2005) or with finite element methods (Hoefsloot \& Verweij 2006). During construction, the short-term surface settlements are monitored and compared with the prediction. The most common method of monitoring is by robotic total stations, that send the measurement data in real-time to the tunnel boring machine (TBM). Based on this data, the operator of the machine can adjust the boring process to minimise the settlements.

Additionally, in the years, and even decades, after construction also long-term settlements can occur, depending on the soil conditions and the tunnel lining (Shirlaw 1995, Mair 2008 and Wongsaroj et al., 2013). According to Shirlaw (1995) long-term settlements can account for 30-90\% of the total cumulative settlement in clayey soils. In case these settlements occur, they may also lead to damage of buildings. But because the robotic total stations are usually removed after the construction of the tunnel, very little data is available of the long-term surface settlements.

In the past decades, satellite radar imaging, using the Interferometric Synthetic Aperture Radar (InSAR) technique, was used to monitor the displacements of the land surface surface (Hanssen 2001, Özer et al. 2019, Gabriel et al. 1989, Ferretti et al. 2001, Crosetto et al. 2016). InSAR was applied in a few tunnel projects to detect the surface settlements during the construction phase (Giardina et al., 2019, Barla et al., 2016, ITAtech Guidelines 2015). InSAR proved to be a powerful tool, and can be used for (i) the detection of tunnelling-induced settlements, resulting in a localization and timing of a settlement, and potentially (ii) the estimation of the quantitative amount of settlement. Estimation of abrupt and localized movements is mainly limited by the revisit times of the satellites, and the coherence condition-the reflection characteristics of the geo-objects should remain relatively unaltered (Hanssen 2001). Moreover, due to the given wavelength of the radar instrument, abrupt changes in the spatial displacement gradients greater than a quarter of the signal wavelength (e.g., $8 \mathrm{~mm}$ for the TerraSAR-X satellite) per repeat cycle and per measurement spacing, may lead to an underestimation of the deformation signal.

Usually short-term settlements during construction of a shield tunnel have a magnitude of a few millimetres to a few centimetres and occur within a distance of 4 to 5 times the TBM length (i.e. 40 to $50 \mathrm{~m}$ ) away from the tunnel axis and parallel to the tunnel 
axis. (See Figure 1). Therefore, at a normal advance rate of the TBM, such settlements above each cross section of the tunnel occur in roughly one week (Broere 2017). Thus, it depends on the spatial distribution of the InSAR measurement points whether such signals can be detected and estimated. This spatial distribution is strongly case-study dependent.

In this paper we analyse and evaluate the use of InSAR data in bored tunnel projects. A special focus is given to the influence of the InSAR phase ambiguities in relation to the short-term settlements that may occur during tunnel construction. We use the twin shield tunnels of the North-South Line in Amsterdam that were excavated in 2011 and 2012 as a case. Second, we investigate with InSAR data if there are longterm settlements in the surroundings of these tunnels.

\section{BACKGROUND}

\subsection{Surface Settlement due to Tunneling}

Shield tunnels are excavated with a tunnel boring machine (TBM). During the excavation process, settlements occur due to insufficient support at face, overexcavation, soil relaxation and inefficient tail void filling. And although modern TBMs have good control of the support pressure and grouting of the tail void, still some surface settlements can occur. Figure 1 shows the development of surface settlement as a tunnel progresses.

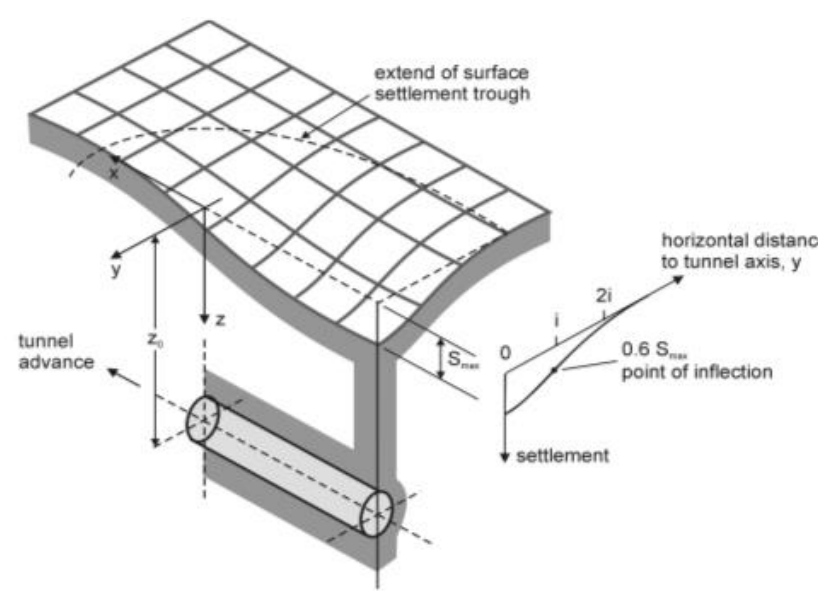

Figure 1: Three-dimensional representation of surface settlement induced by a tunnel (Attewell, Yeates and Selby, 1986)

In practice, the settlements that occur during construction in cross-sectional direction of the tunnel are often calculated with Peck's formula (Peck 1969). This empirical formula is based on observations and analyses of a very large amount of monitoring data from tunnels and is most commonly used for 2D calculations. According to Peck, the settlement trough that occurs in a cross-section perpendicular to the tunnel axis has the same shape as a Gaussian curve (See Figure 2). The major assumption is that the volume of the settlement trough equals the volume of soil losses around the tunnel.
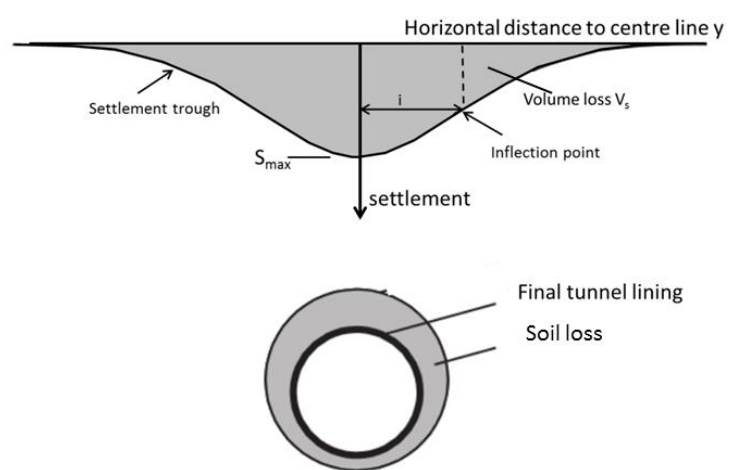

Figure 2: Settlement trough in the shape of a Gaussian Curve (after O’Reilly \& New, 1982)

Usually these settlements occur within a length of 40 to $50 \mathrm{~m}$, which corresponds to roughly one week of construction (Broere and Festa, 2017). Thus, the relevant gradients can be expressed in the unit $\left[\mathrm{m} \mathrm{m}^{-1} \mathrm{~d}^{-}\right.$ ${ }^{1}$ ], where $\mathrm{m}$ are meters and $\mathrm{d}$ represents days. During construction the surface settlements are monitored with automatic total stations that measure the ground surface and building displacements.

Additionally, long-term settlements may occur in the years, and even decades, after construction due to consolidation and creep of clayey soils. The magnitude of these settlements can account for $30-90 \%$ of the total settlements (Shirlaw 1995) However, only a few studies were performed on long-term settlements for tunnels and there are large uncertainties in the predictions (Mair 2008 ,Wongsaroj et al. 2013). Moreover, as the monitoring of the surface typically ends soon after tunnel completion, very limited long-term settlements data is available.

\subsection{Basic Concepts of Interferometric Synthetic Aperture Radar (InSAR)}

Over the last decades, Synthetic Aperture Radar (SAR) has become a powerful tool to monitor displacements of the Earth's surface (Hanssen 2001, Özer et al. 2019, Gabriel et al. 1989, Ferretti et al. 2001, Crosetto et al. 2016). A SAR is an imaging radar, mounted on a satellite, that sends pulses of electromagnetic waves to the earth. Part of these pulses reflect back towards the antenna of the satellite. The phase of the incoming signal, which is dependent on the two-way travel time of the signal, is recorded. A single phase observation $\varphi_{M}$ in one SAR acquisition does not contain interpretable information. However, when obtaining a second phase observation $\varphi_{\mathrm{P}}$, at a different location, and subsequently repeating those measurements in a second radar acquisition during the next satellite pass, the double-difference (spatial 
and temporal phase difference) $\Delta \varphi_{\text {Int }}$ between the two measurements can be determined, i.e. the interferometric phase (See Figure 3).

$$
\Delta \varphi_{\text {Int }}=\left(\varphi_{M}-\varphi_{P}\right)_{t 2}-\left(\varphi_{M}-\varphi_{P}\right)_{t 1}
$$

By calculating the interferometric phase for each successive image, a time series of displacements is obtained.
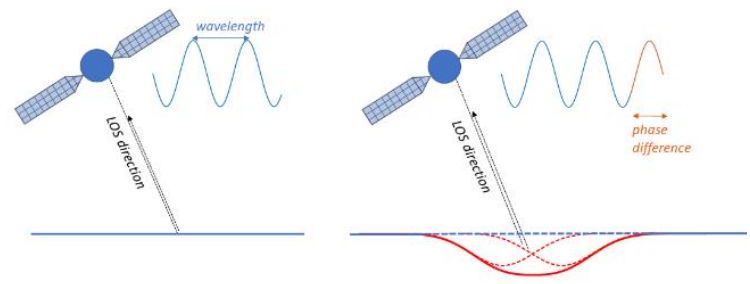

Figure 3: Two sequential InSAR measurement before and after deformation due to tunnel construction (after Ozer et al. 2019). The LOS is the line of sight direction of the radar signal.

The relation between phase and deformation is given by

$\Delta \varphi_{\text {int }}=\frac{2 \pi}{\lambda} \cdot 2 D=\frac{4 \pi}{\lambda} \cdot D$,

where $2 D$ is the extra distance between satellite and target and back to the satellite, and $\lambda$ is the radar wavelength. If a pixel has displaced more than $\pi$, a multiple of $2 \pi$ has to be added or subtracted from the interferometric phase to get the correct phase change, that is

$$
\psi=\Delta \varphi_{\text {int }}+2 \pi k \quad k \in \mathbb{N}
$$

This procedure is called phase unwrapping. The phase interval of $\pi$ radians corresponds with a physical displacement of $1 / 4$ of the physical radar wavelength, which is typically either 31 or $56 \mathrm{~mm}$, in the line of sight direction to the radar. Figure 4 shows an example of a InSAR time series. Point $\mathrm{A}$ is at around $1 / 4$ wavelength of the deformation model and could be estimated with ambiguous phase shifts, leading to different unwrapping solutions.

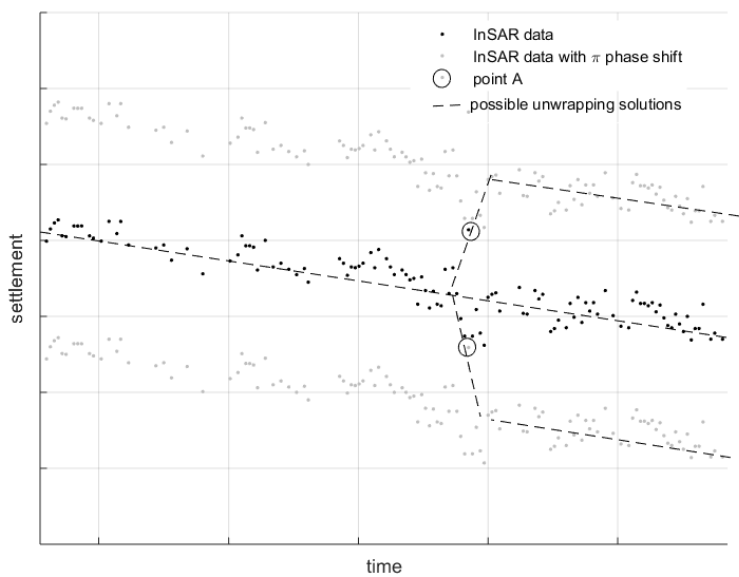

Figure 4: Fictious example of unwrapping solutions for an InSAR time serie.

This means, that if displacements are larger than $1 / 4$ of the physical radar wavelength, a-priori knowledge is required to estimate the correct displacement $\psi$. In the case of a shield tunnel excavation, the moment in time that the TBM is passing and the expected settlements can be used to process InSAR data without ambiguity errors.

A reflection from the ground may consist of multiple scatterers. There of two type of scatterers: Distributed Scatterers (DS) and Point Scatterers (PS). PS are pixels where there is one dominant reflecting object within the pixels footprints that show constant behaviour over time. DS are pixels where there are multiple objects with a weaker reflection but that show also constant behaviour over time.

The interpretation of double-difference measurements requires an arbitrary reference point. The movement of all points within the analysis is relative to this reference point.

\section{METHOD}

We use the twin shield tunnels of the North-South metroline in Amsterdam. For one cross section of the track, we first predict the surface settlement during construction and use this as a-priori information to unwrap a few selected InSAR points. Then we select the most likely unwrapping solution and use this to unwrap all InSAR points in this cross section. Next we verify this outcome with the traditional monitoring of the surface levelling points during construction. If both time series correspond well during construction, we use the InSAR to evaluate the long-term settlements. Figure 5 gives a schematic overview of the research steps. 


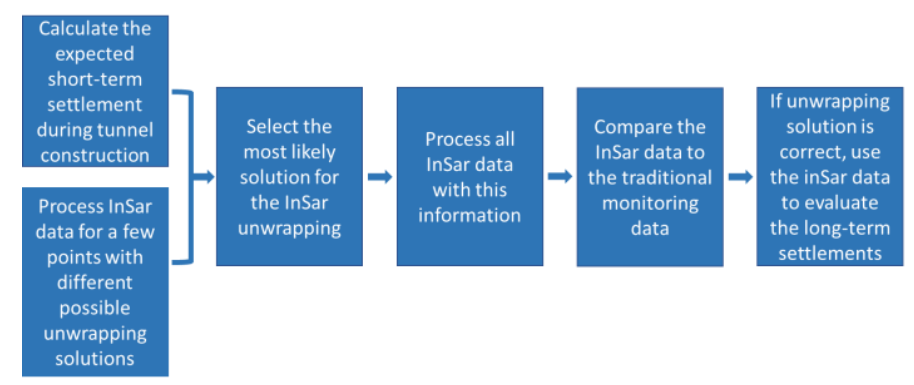

Figure 5: Research Steps for comparing traditional measurements to InSAR data.

\section{CASE STUDY NORTH-SOUTH LINE}

Between 2010 and 2012 the twin shield tunnels of the North-South line were excavated with a slurry tunnel boring machine (TBM). The track is located between Scheldeplein and Centraal Station, is $3.8 \mathrm{~km}$ long and consists of three deep intermediate stations: Ceintuurbaan, Vijzelgracht and Rokin. In this research we focus on the line between Scheldestraat and Ceintuurbaan (See Figure 6).

At the beginning of this trajectory, from Scheldestraat to Cornelis Troostplein, the tubes are located next to each other with a spacing of $3.75 \mathrm{~m}$. The tunnels have a diameter of $6.52 \mathrm{~m}$, the depth of the axis varies from $17 \mathrm{~m}$ to $24 \mathrm{~m}$. The tubes are mostly located in sand or clayey sand (See Figure 7). Both tubes in this trajectory were drilled from South to North with a slurry TBM. The West tunnel (numbered with [1] in Figure 7) was drilled in 2011 and the East tunnel (numbered with [2] in Figure 7) in 2012. The TBM of the West tunnel passed Churchilllaan on June $27^{\text {th }} 2011$ and the TBM of the East tunnel passed Churchilllaan on January $27^{\text {th }} 2012$.

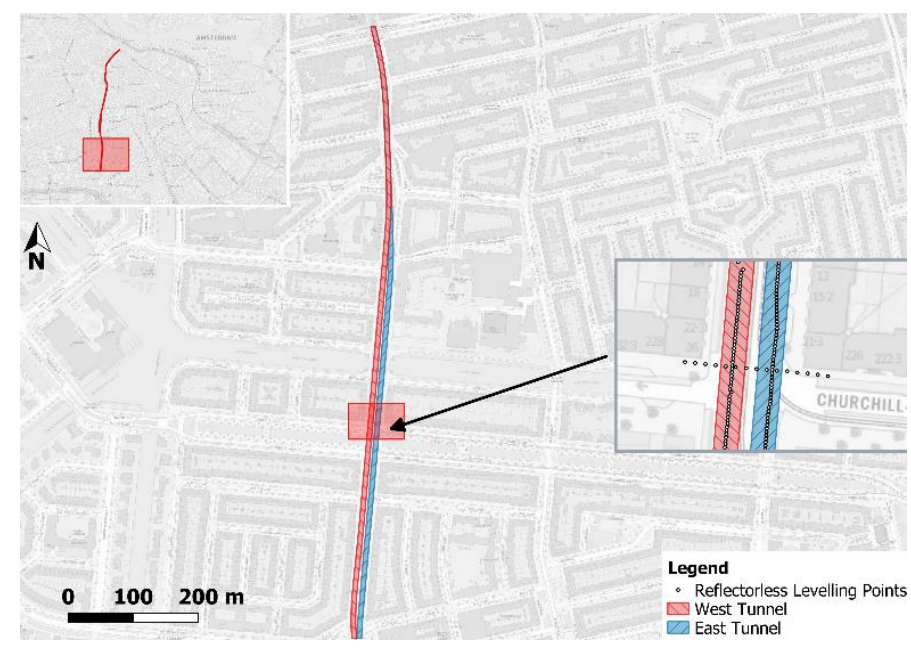

Figure 6: South part of the track of the North-South line.

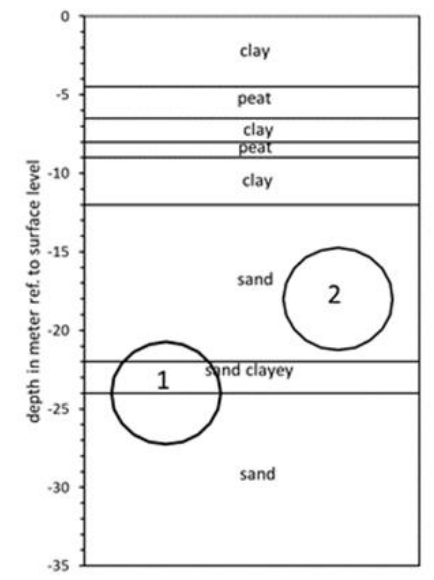

Figure 7: Simplified soil profile and location of tunnels at Churchilllaan.

\subsection{Traditional Monitoring Data}

During the construction of the North-South line, the buildings in the influence zone of the tunnel and the surface were extensively monitored with robotic total stations (Van Der Poel et al. 2006, Cook et al., 2007). On the buildings, prisms were installed that were measured by the total stations (Korff \& Mair 2013). In order to measure the ground settlement, the automatic total stations recorded the vertical heights of points positioned on a virtual horizontal grid without the need for prisms on the surface. This is known as reflectorless surface levelling.

In the line of the axis of each tunnel, the surface was measured hourly every meter. Furthermore, at several locations also points perpendicular to the tunnel axis were measured to obtain a transversal settlement profile. In the detail in Figure 6 the reflectorless surface levelling points are shown for the Churchilllaan.

The monitoring started approximately 2 months before the TBM passed and ended 1 month after passing of the TBM. Both the surface and structures in the expected influence zone of the tunnel were extensively monitored. In this research we only use the data of the reflectorless surface levelling points on the ground.

\subsection{InSAR Data}

For the chosen trajectory, we use SAR data acquired between 2009 to 2018 by the TerraSAR-X satellite. The data set is acquired from the ascending orbit (i.e., the satellite passes from South to North) and since the antenna is pointing to the right, the radar line of sight direction is roughly West-East. The revisit time of the satellite is 11 days and the radar wavelength $\lambda$ is 31 $\mathrm{mm}$.

The displacements are measured in the line of sight of the satellite, with an incidence angle of 32 degrees 
with respect to zenith. Therefore, the measurements are sensitive to both vertical and horizontal deformation components. In our study we assume that the horizontal displacements are small and therefore we transformed the measured displacement in the vertical direction.

We use only measurements points on the ground surface. Points at $1.5 \mathrm{~m}$ or higher above surface level are discarded from the analyses because they are assumed to be on buildings. Figure 8 shows the InSAR points at the Churchilllaan.

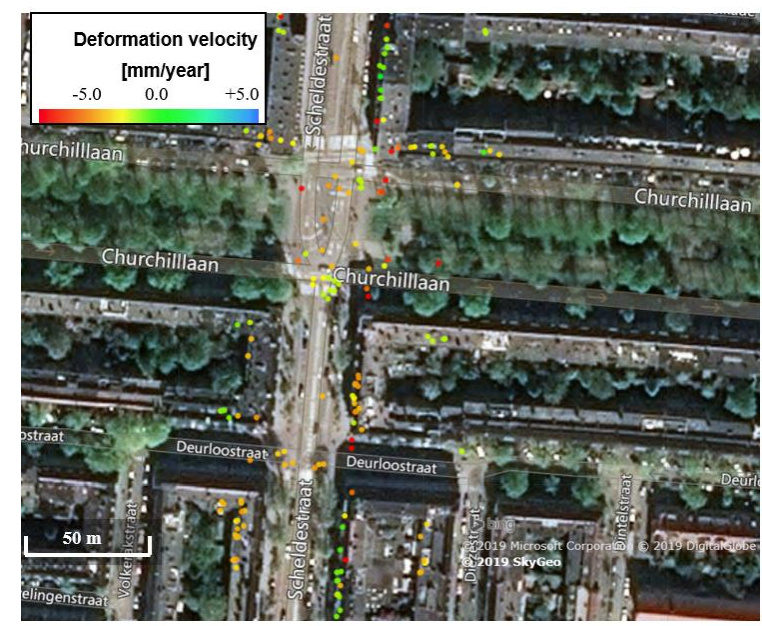

Figure 8: InSAR points near Churchilllaan.

We use Distributed Scatterers (DS) and Persistent Scatterers (PS) in our research. Since InSAR data is relative both in time and space, references have to be adopted. In the time domain, the first measurement in the displacement time series are set to zero. In the spatial domain, the average deformation rate of the complete dataset over Amsterdam is set to zero. It should be noted that these choices are completely arbitrary and that this should be considered in the interpretation of the results.

\section{ANALYSES}

First, based on the soil profile, the depth of the tunnels and the expected a-priori volume loss, the settlement trough for both cross sections was calculated with Peck (1969). We used a common average volume loss of $0.5 \%$ during tunnel construction ( $\mathrm{Vu}$, Broere and Bosch, 2016) and assumed a normal distribution with a standard deviation of $0.25 \%$ for the volume loss.

At tunnel 1 at Churchilllaan, this resulted in an average maximum settlement of $10 \mathrm{~mm}$ (See Figure 9). The standard deviation of the settlement was $4.9 \mathrm{~mm}$ and based on the probability density function, the probability of a settlement larger than $1 / 4$ of the wavelength, $7.8 \mathrm{~mm}$, was a $70 \%$ (See Figure 10). As the settlements during construction occur in less than 1 week, while the satellite passes once every 11 days, there is a large likelihood that the displacement between two InSAR measurement points at a distance of 15 meters or more, the 11-day displacement is greater than $7.8 \mathrm{~mm}$.

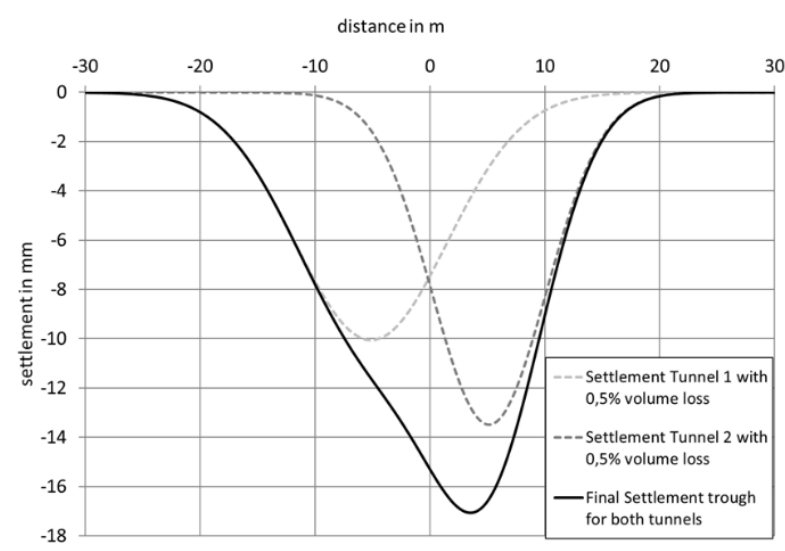

Figure 9: Settlement trough at Churchilllaan with $0.5 \%$ volume loss.

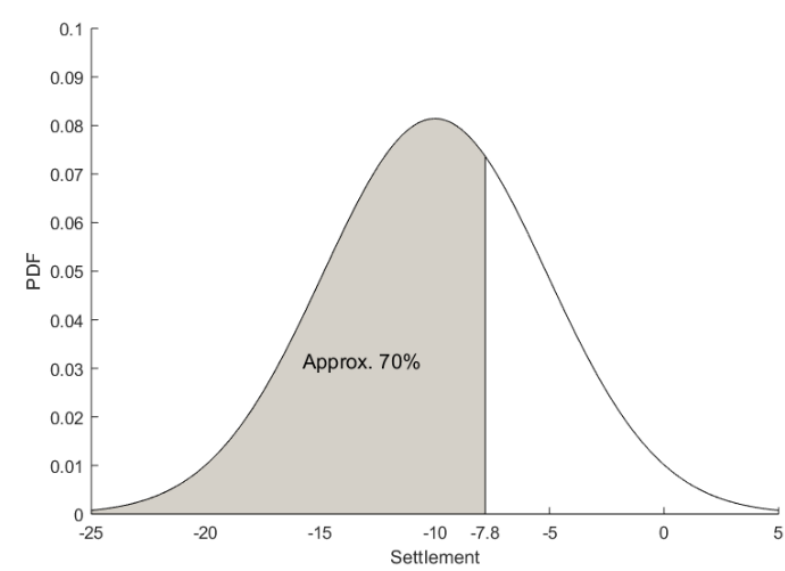

Figure 10: Probability Density Function for the Maximum Settlement of Tunnel 1 at Churchilllaan.

Second, as we expect that the displacement between two points at a distance of $15 \mathrm{~m}$ or more might be greater than $1 / 4$ of the wavelength within 11 days, phase unwrapping errors may occur. To estimate the correct phase ambiguity, we selected two InSAR points in the tunnel axis of tunnel 1 (See Figure 11) and processed them with three different phase shifts at the time that the first tunnel was constructed in June 2011. The points were chosen at a location where also traditional monitoring data is available.

The time series with the different ambiguity levels of points 1 and 2 are shown in Figure 12. 


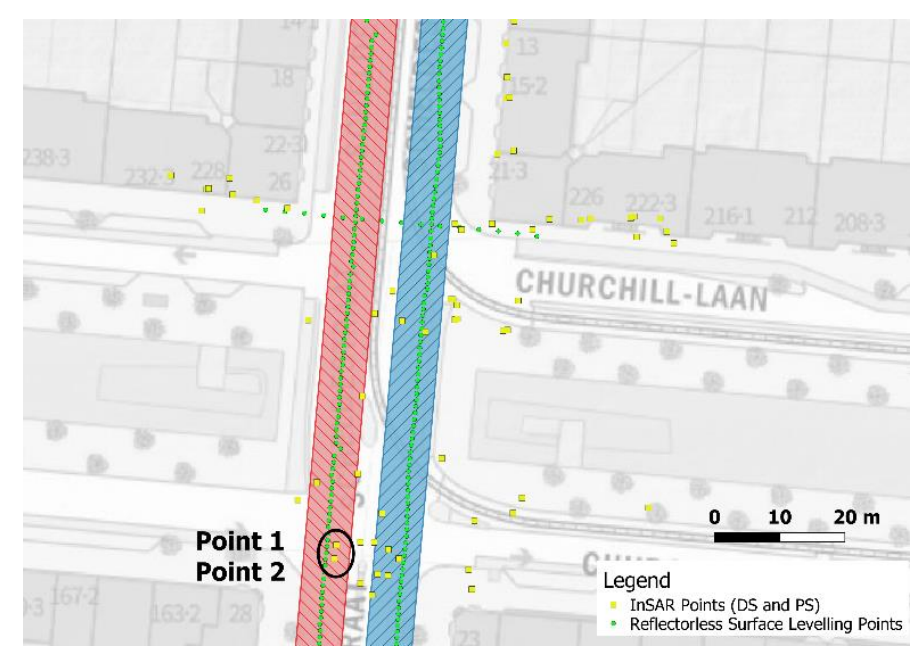

Figure 11: Surface Levelling Surface Points and InSAR Data Points at Churchilllaan.
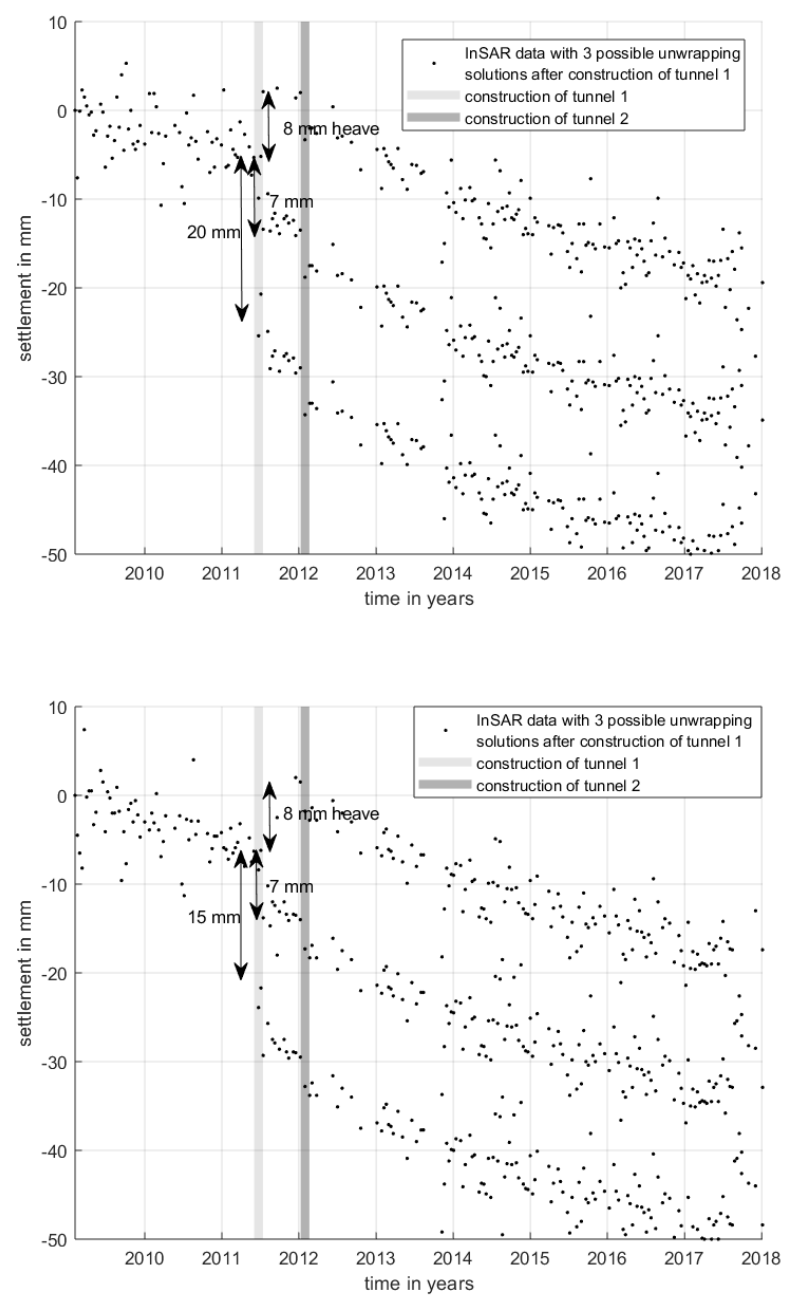

Figure 12: Unwrapping possibilities at Churchilllaan, point 1 (top) and point 2 (bottom)

Based on the plotted figures, we could determine visually the most probable solution for the time series. The upper time series shows heave, which has a probability of $2 \%$ based on the settlement calculation, the lower time series shows a settlement of $15 / 20 \mathrm{~mm}$ which also has a probability of $2 \%$. Therefore the middle option, with $7 \mathrm{~mm}$ settlement is the most likely solution.

Third, we verified this solution with the surface levelling data at this location (See Figure 13).
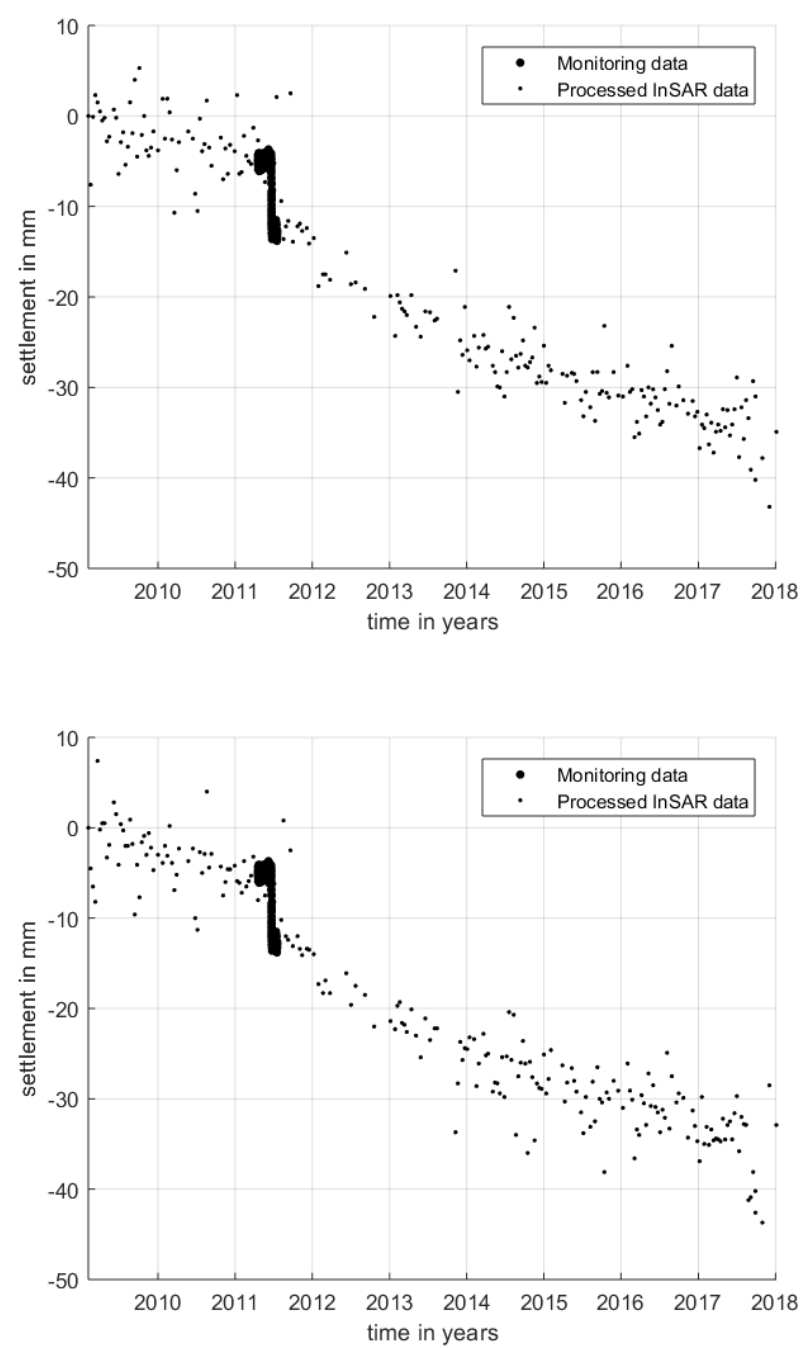

Figure 13: Comparison Unwrapping Solution InSAR with Surface Leveling Points, point 1 (top) and point 2 (bottom).

Based on the figures, we conclude that the middle option for the processing was correct and we use this information to process all other InSAR points at the Churchilllaan. Figure 14 shows the location of the InSAR points and the reflectorless surface leveling points.

In the marked area with locations $\mathrm{A}, \mathrm{B}, \mathrm{C}$ and $\mathrm{D}$ a detail comparison was performed (see Figure 15). The figures show good agreements between the InSAR data and the traditional surface levelling. 


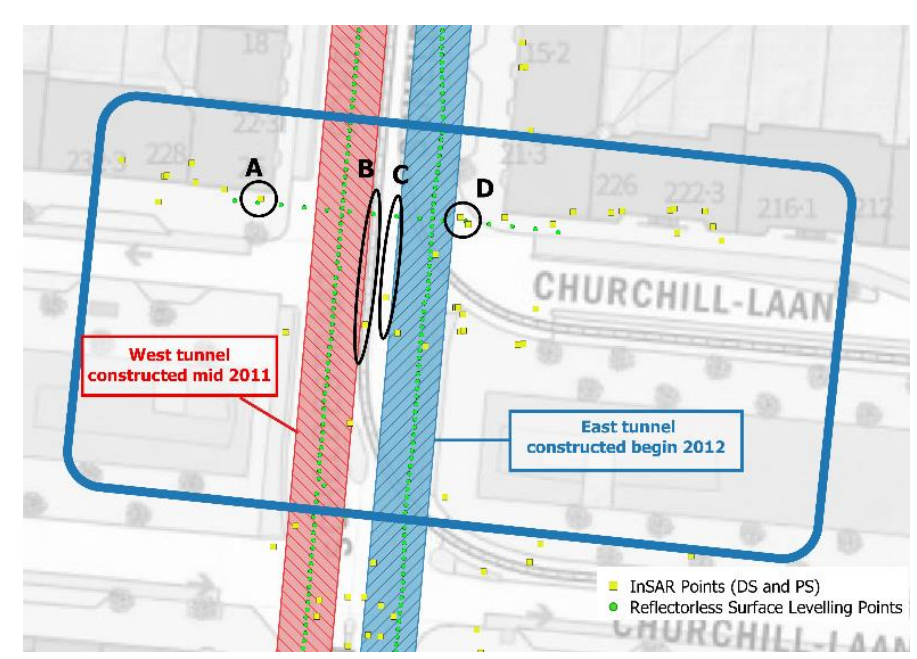

Figure 14: Location InSAR data and levelling points at Churchilllaan.
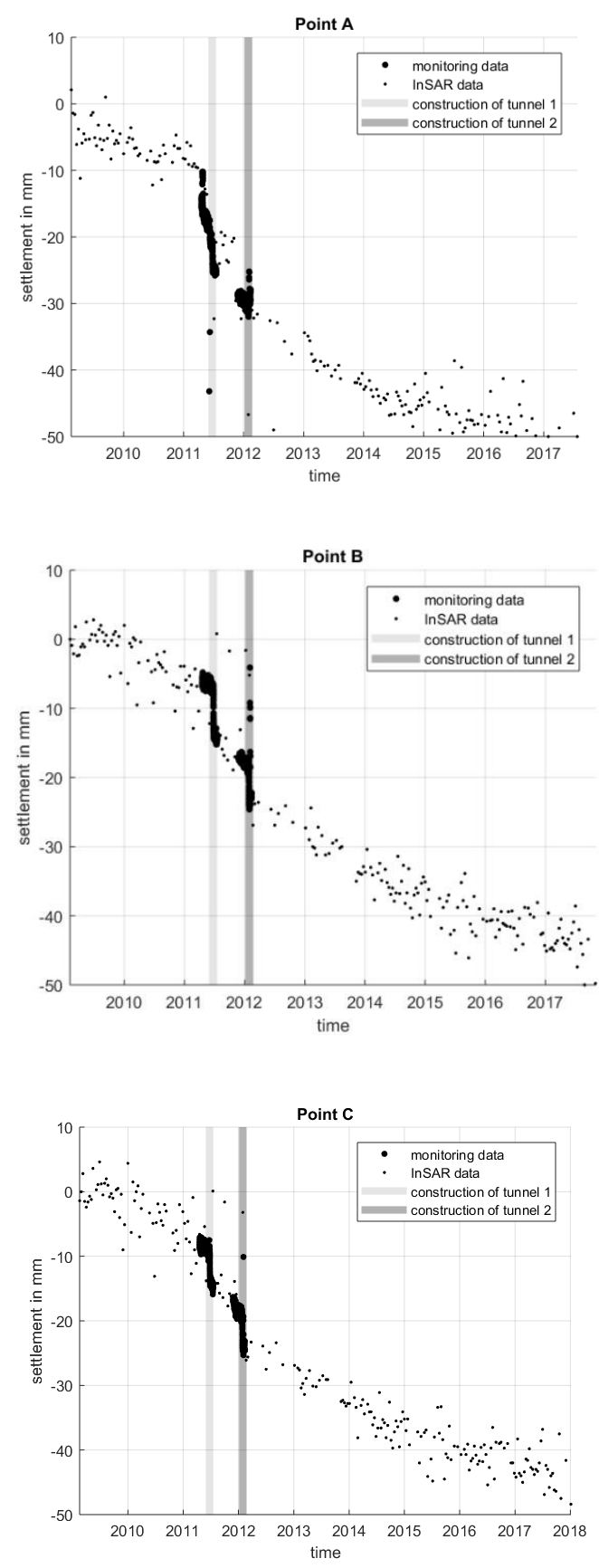

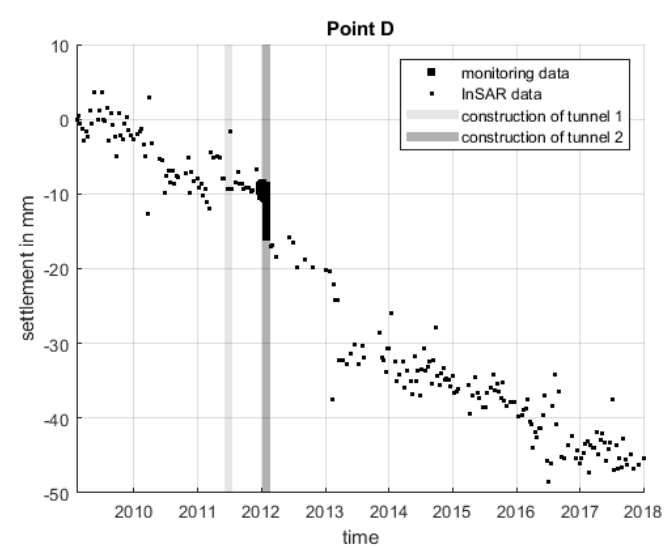

Figure 15: Comparison InSAR and Surface Levelling Data, Points at Point A, B, C and D.

Light grey area=moment that the TBM passes for tunnel 1; Dark grey area=moment that the TBM passes for tunnel 2 .

Finally we used InSAR to evaluate the long-term settlements. We discovered that the settlement velocity changed prior to the passing of the TBM's (See Figure 16). One of the reasons could be the construction at this location of two vertical shafts of around $30 \mathrm{~m}$ deep that will serve as an emergency exit for the tunnels. The shafts were excavated in the wet by pushing prefabricated concrete elements into the ground and excavating within these concrete rings. After complete excavation, the shafts were pumped dry around end 2010, thus around 6 months before tunnel 1 was excavated. This would correspond well to a change in the settlement velocity in the InSAR data. This hypothesis will be investigated in the future.

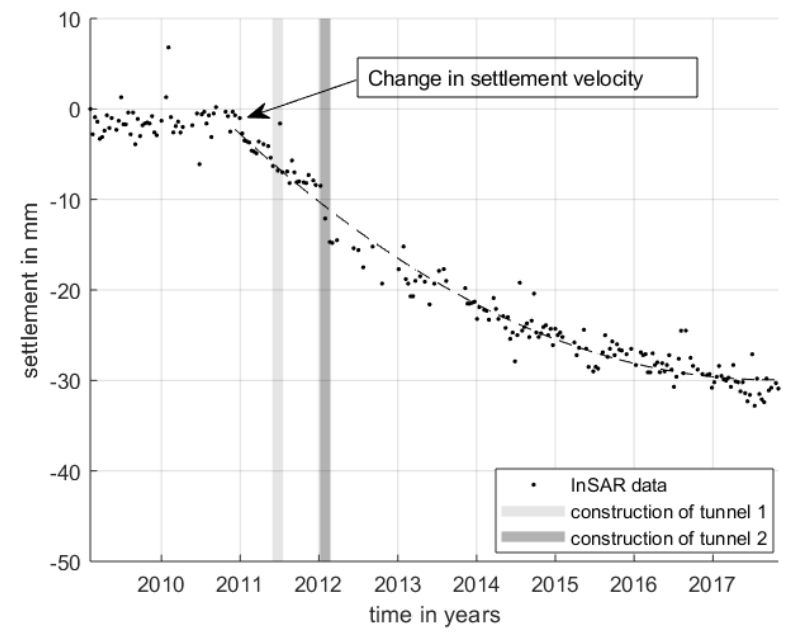

Figure 16: Long-term settlement at Churchilllaan in the vicinity of a vertical shaft.

\section{CONCLUSION}

In this research we compared InSAR monitoring data to traditional monitoring data (reflectorless surface levelling) during the construction phase of two shield 
tunnels that were excavated in 2011 and 2012 in Amsterdam for the North-South metro line. From the analyses the following conclusions can be drawn:

Prior information about the expected settlements is needed to process the InSAR data correctly. When using this prior information, the most probable unwrapping solution for the InSAR can be selected. The correct unwrapping solution InSAR can capture the short-term settlement that occur immediately during construction of the shield tunnel. InSAR cannot replace the traditional monitoring but due to its high spatial resolution and the availability of time series from 2009 until present, it is a valuable complementary source of information. InSAR provides data outside the area of the levelling points and it gives information about settlement patterns prior and after construction.

\section{AKNOWLEDGEMENTS}

The authors wish to thank the Municipality of Amsterdam for providing the surface leveling data.

\section{REFERENCES}

Attewell, P. B., Yeates, J. and Selby, A. R. 1986. Soil movements induced by tunnelling and their effects on pipelines and structures. doi: 10.1016/0886-7798(87)90195-7.

Barla, G. et al. 2016. InSAR monitoring of tunnel induced ground movements', Geomechanik und Tunnelbau, 9(1), pp. 15-22. doi: 10.1002/geot.201500052.

Broere, W. and Festa, D. 2017. Correlation between the kinematics of a Tunnel Boring Machine and the observed soil displacements, Tunnelling and Underground Space Technology. doi: 10.1016/j.tust.2017.07.014.

Cook, D., De Nijs, R. and Frankenmolen, S. 2007. Amsterdam Noord/Zuidlijn: Use of background monitoring data prior to construction commencement, in Geotechnical Special Publication. doi: 10.1061/40940(307)13.

Crosetto, M. et al. 2016. Persistent Scatterer Interferometry: A review', ISPRS Journal of Photogrammetry and Remote Sensing. doi: 10.1016/j.isprsjprs.2015.10.011.

Ferretti, A., Prati, C. and Rocca, F. 2001. Permanent scatterers in SAR interferometry', IEEE Transactions on Geoscience and Remote Sensing. doi: 10.1109/36.898661.

Gabriel, A. K., Goldstein, R. M. and Zebker, H. A. 1989. Mapping small elevation changes over large areas: differential radar interferometry', Journal of Geophysical Research. doi: 10.1029/JB094iB07p09183.

Giardina, G. et al. 2019. Evaluation of InSAR monitoring data for post-tunnelling settlement damage assessment', Structural Control and Health Monitoring. doi: 10.1002/stc.2285.

Hoefsloot, F. J. M. and Verweij, A. 2006. 4D grouting pressure model PLAXIS', in Geotechnical Aspects of Underground Construction in Soft Ground - Proceedings of the 5th International Conference of TC28 of the ISSMGE. doi: 10.1201/noe0415391245.ch72.

Kaalberg, F. J. et al. 2005. Dutch research on the impact of shield tunnelling on pile foundations', in Proceedings of the 16th International Conference on Soil Mechanics and Geotechnical Engineering: Geotechnology in Harmony with the Global Environment. doi: 10.1201/noe0415391245.ch13.

Korff, M. and Mair, R. J. 2013. Ground displacements related to deep excavation in Amsterdam', in 18th International Conference on Soil Mechanics and Geotechnical Engineering: Challenges and
Innovations in Geotechnics, ICSMGE 2013.

Loganathan, N., Poulos, H. G. and Xu, K. J. 2001. Ground and pilegroup responses due to tunnelling', Soils and Foundations. doi: 10.3208/sandf.41.57.

Mair, R. J. 1993. Unwin Memorial Lecture 1992 Developments in geotechnical engineering research: Application to tunnels and deep excavations', Proceedings of the Institution of Civil Engineers: Civil Engineering. doi: 10.1680/icien.1993.22378.

Mair, R. J. 2008. Tunnelling and geotechnics: New horizons', Geotechnique, 58(9), pp. 695-736. doi: 10.1680/geot.2008.58.9.695.

Mark, P. et al. 2012. Radarinterferometrie zum Setzungsmonitoring beim Tunnelbau: Anwendung am Beispiel der Wehrhahn-Linie in Düsseldorf', Bautechnik, 89(11), pp. 764-776. doi: 10.1002/bate.201200035.

O'Reilly, M. P. and New, B. M. 1982. Settlements above tunnels in the United Kingdom - their magnitude and prediction.', Tunnelling ' 82. Papers presented at the 3rd international symposium. doi: 10.1016/0148-9062(83)91768-0.

Özer, I. E. et al. 2019. Applicability of satellite radar imaging to monitor the conditions of levees', Journal of Flood Risk Management. doi: $10.1111 /$ jfr3.12509.

Peck, R. B. 1969. Deep Excavations and Tunneling in Soft Ground', in 7th International Conference on Soil Mechanics and Foundation Engineering.

Van Der Poel, J. T., Gastine, E. and Kaalberg, F. J. 2006. Monitoring for construction of the North/South metro line in Amsterdam, The Netherlands', in Geotechnical Aspects of Underground Construction in Soft Ground - Proceedings of the 5th International Conference of TC28 of the ISSMGE. doi: 10.1201/noe0415391245.ch103.

Sagaseta, C. 1987. Analysis of undrained soil deformation due to ground loss', Geotechnique. doi: 10.1680/geot.1987.37.3.301.

Selemetas, D., Standing, J. R. and Mair, R. J. 2006. The response of full-scale piles to tunnelling', in Geotechnical Aspects of Underground Construction in Soft Ground - Proceedings of the 5th International Conference of TC28 of the ISSMGE. doi: 10.1201/noe0415391245.ch106.

Shirlaw, J. N. 1995. Observed and calculated pore pressures and deformations induced by an earth balance shield: Discussion', Canadian Geotechnical Journal. doi: 10.1139/t95-017.

Verruijt, A. and Booker, J. R. 1996. Surface settlements due to deformation of a tunnel in an elastic half plane', Geotechnique. doi: 10.1680/geot.1996.46.4.753.

Vu, M. N., Broere, W. and Bosch, J. 2016. Volume loss in shallow tunnelling', Tunnelling and Underground Space Technology. doi: 10.1016/j.tust.2016.06.011.

Wongsaroj, J., Soga, K. and Mair, R. J. 2013. Tunnelling-induced consolidation settlements in London Clay', Geotechnique. doi: 10.1680/geot.12.P.126. 